\title{
A Green Recyclable Poly(4-vinylpyridine)-Supported Copper Iodide Nanoparticles Catalyst for the Multicomponent Synthesis of 3,4-dihydropyrimidin-2(1H)-ones/thiones
}

\author{
Jalal Albadi*, Azam Mansournezhad ${ }^{\dagger}$, Mojtba Baghernehad ${ }^{\dagger}$, and Nasrin Frozan ${ }^{\dagger}$ \\ College of science, Behbahan Khatam Alanbia University of Technology, Behbahan, Iran. \\ *E-mail: Chemalbadi@gmail.com \\ ${ }^{\dagger}$ Department of chemistry, Gachsaran Branch, Islamic Azad University, Gachsaran, Iran \\ (Received October 15, 2012; Accepted January 29, 2013)
}

Key words: Poly(4-vinylpyridine)-supported, Copper(I) catalysis, Biginelli reaction, 3,4-dihydropyrimidin-2(1H)-ones/thiones, Solvent-free conditions

Dihydropyrimidone derivatives are important class of compounds that received significant attention from many pharmaceutical and organic chemists because of the broad spectrum of their biological and pharmaceutical properties such as antibacterial, anti-inflammatory, and antivirial properties. ${ }^{1}$ The initial synthesis of dihydropyrimidone was reported by Biginelli involving a one pot condensation of an aldehydes, $\beta$-ketoester and urea under acidic conditions. ${ }^{2}$ However, this reaction suffers from the harsh conditions, long reaction times and low yields of the products. In order to improve the efficiency of this reaction, several modified procedures have been reported. ${ }^{3-17}$ Recently, the application of $\mathrm{CuI}$ as the catalyst for the Bignielli reaction have been reported. ${ }^{18}$ However, in spite of its application potentials, $\mathrm{CuI}$ have some limitations such as thermodynamic instability, long reaction times, non-recyclable, toxicity and difficulty in separation of the product from the reaction medium. Such drawbacks could be obviated by using the supported catalyst. Nitrogen-based polymer have been shown to protect the metal center from oxidation and disproportionation, while enhancing its catalytic activity. ${ }^{19-21}$ To improve the recovery and reuse, copper species have been immobilized on the various supports such as carbon, ${ }^{22}$ amine-functionalized polymers, ${ }^{23}$ zeolites, ${ }^{24}$ amine-functionalized silica ${ }^{25}$ and aluminum oxyhydroxide fiber. ${ }^{26}$ Poly(4-vinylpyridine)-supported reagents are active for various organic reactions including oxidations, reductions and halogenations. Simple recovery from reaction mixtures, their reusability, compatibility with a wide range of solvents, physical stability, and their toleration of a great number of reaction conditions bodes well for the future of $\mathrm{P}_{4} \mathrm{VPy}-$ supported reagents in which their properties can be finetuned for specific chemical transformations. ${ }^{27}$ In recent years, nano-catalysts has emerged as a sustainable and competitive alternative to conventional catalysits since the nanoparticles possess a high surface-to-volume ratio, which enhances their activity and selectivity, while at the same time maintaining the intrinsic features of a heterogeneous catalyst. ${ }^{28}$ In particular, the immobilization of copper(I) salts nanoparticles on high-surface-area supports allows a higher stability and dispersity of the particles as well as a further exploitation of the special activity and recycling properties of the catalyst. Recently, we have reported the preparation of copper iodide nano particles supported on poly(4-vinylpyridine) $\left(\mathrm{P}_{4} \mathrm{VPy}-\mathrm{CuI}\right)$ and its application for the click synthesis of triazole derivatives. ${ }^{29-30}$ In continuation of these studies and our research on the synthesis of dihydropyrimidinone derivatives, ${ }^{31}$ herein, we wish to report the applicability of this reagent for the synthesis of dihydropyrimidone derivatives (DHPMs) under solvent-free conditions (Scheme 1).

\section{EXPRIMENTAL}

\section{General Procedure}

A mixture of aldehyde ( $1 \mathrm{mmol}), \beta$-ketoester $(1 \mathrm{mmol})$, urea or thiourea $(1 \mathrm{mmol})$ and $\mathrm{P}_{4} \mathrm{VPy}-\mathrm{CuI}(0.1 \mathrm{~g})$ was heated in an oil bath $\left(80^{\circ} \mathrm{C}\right)$ for the appropriate time (Table 1). After completion of the reaction as followed by TLC, $5 \mathrm{~mL}$ of ethyl acetate was added to the mixture and

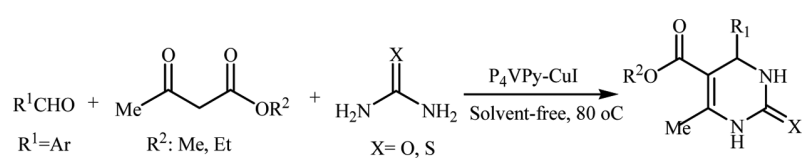

Scheme 1. Synthesis of dihydropyrimidone derivatives catalyzed by $\mathrm{P}_{4} \mathrm{VPy}-\mathrm{CuI}$. 
Table 1. Synthesis of dihydropyrimidone derivatives catalyzed by $\mathrm{P}_{4} \mathrm{VPy}-\mathrm{CuI}$

\begin{tabular}{|c|c|c|c|c|c|c|}
\hline Entry & $\mathrm{R}^{1}$ & $\mathrm{R}^{2}$ & $X$ & $\begin{array}{l}\text { Time } \\
(\mathrm{min})\end{array}$ & $\begin{array}{l}\text { Yield } \\
(\%)^{a}\end{array}$ & $\begin{array}{l}\text { M.P. } \\
\left({ }^{\circ} \mathrm{C}\right)^{b}\end{array}$ \\
\hline 1 & $\mathrm{Ph}$ & $\mathrm{Et}$ & $\mathrm{O}$ & 10 & 92 & $203-205$ \\
\hline 2 & 2-Cl-Ph & Et & $\mathrm{O}$ & 12 & 90 & 214-216 \\
\hline 3 & 4-Cl-Ph & $\mathrm{Et}$ & $\mathrm{O}$ & 10 & 94 & $210-212$ \\
\hline 4 & $3-\mathrm{NO}_{2}-\mathrm{Ph}$ & Et & $\mathrm{O}$ & 13 & 88 & $227-229$ \\
\hline 5 & $4-\mathrm{NO}_{2}-\mathrm{Ph}$ & Et & $\mathrm{O}$ & 8 & 89 & 209-211 \\
\hline 6 & 4-Me-Ph & Et & $\mathrm{O}$ & 18 & 92 & $214-216$ \\
\hline 7 & 4-MeO-Ph & $\mathrm{Et}$ & $\mathrm{O}$ & 20 & 90 & 201-203 \\
\hline 8 & 4-F-Ph & Et & $\mathrm{O}$ & 12 & 89 & $181-183$ \\
\hline 9 & $\mathrm{Ph}$ & Et & $\mathrm{S}$ & 10 & 90 & $206-208$ \\
\hline 10 & 2-MeO-Ph & $\mathrm{Et}$ & $\mathrm{S}$ & 16 & 90 & $256-258$ \\
\hline 11 & 4-Cl-Ph & Et & $\mathrm{S}$ & 10 & 92 & $183-185$ \\
\hline 12 & $3-\mathrm{NO}_{2}-\mathrm{Ph}$ & Et & $\mathrm{S}$ & 14 & 88 & 205-207 \\
\hline 13 & $\mathrm{Ph}$ & $\mathrm{Me}$ & $\mathrm{O}$ & 10 & 90 & 209-211 \\
\hline 14 & 4-Cl-Ph & $\mathrm{Me}$ & $\mathrm{O}$ & 12 & 92 & $205-207$ \\
\hline 15 & 4-MeO-Ph & $\mathrm{Me}$ & $\mathrm{O}$ & 20 & 87 & 191-193 \\
\hline 16 & 4-F-Ph & $\mathrm{Me}$ & $\mathrm{O}$ & 15 & 88 & 193-194 \\
\hline 17 & $\mathrm{Ph}$ & $\mathrm{Me}$ & $\mathrm{S}$ & 12 & 89 & $220-222$ \\
\hline 18 & 4-MeO-Ph & $\mathrm{Me}$ & $\mathrm{S}$ & 22 & 90 & $152-153$ \\
\hline 19 & $\mathrm{CH}_{3} \mathrm{CH}_{2} \mathrm{CH}_{2}$ & Et & $\mathrm{O}$ & 60 & - & - \\
\hline 20 & $\mathrm{PhCH}_{2} \mathrm{CH}_{2}$ & $\mathrm{Et}$ & $\mathrm{O}$ & 60 & - & - \\
\hline 21 & $\mathrm{Ph}+\mathrm{CH}_{3} \mathrm{CH}_{2} \mathrm{CH}_{2}$ & Et & $\mathrm{O}$ & 10 & 90 & $203-205$ \\
\hline
\end{tabular}

${ }^{a}$ Isolated yield. ${ }^{b}$ Products were characterized by comparison of their spectroscopic data (NMR and IR) and melting points with those reported in the literature. ${ }^{16-27}$

filtered. The catalyst washed with ethyl acetate, dried and stored for another consecutive reaction run. Evaporation of the solvent from the filtrate and recrystallization of the solid residue from hot ethanol afforded the pure products in high yields.

\section{Determination of the Copper Content in $\mathrm{P}_{4} \mathrm{VPy}-\mathrm{CuI}$}

The $\mathrm{P}_{4} \mathrm{VPy}-\mathrm{CuI}(100 \mathrm{mg})$ was extracted with concentrated $\mathrm{HCl}(5 \times 2 \mathrm{~mL})$ in a screw-capped vessel, followed by treatment with concentrated nitric acid $(2 \mathrm{~mL})$ to digest the metal complex. The mixture was then transferred into a volumetric flask $(100 \mathrm{~mL})$, diluted 1:50 for the second time and was analyzed by the ICP analysis. The copper concentration was determined from the atomic emissions ( $324.754 \mathrm{~nm})$ by reference to a linear $(\mathrm{R}=0.99)$ calibration curve of (1-4 ppm) of CuI prepared in a manner identical to the sample preparation. The loading of supported catalyst was calculated to be $1.32 \mathrm{mmol} \mathrm{CuI \cdot g^{-1 }}$ of prepared catalyst. The same procedure was used to measure the leaching accounts of supported catalyst after 8 consecutive runs.

\section{RESULT AND DISCUSSIONS}

The copper iodide nanoparticles immobilized on poly (4-vinylpyridine) ( $\left.\mathrm{P}_{4} \mathrm{Py}-\mathrm{CuI}\right)$ was readily prepared in a one-step procedure. Poly(4-vinylpyridine) was refluxed with a solution of $\mathrm{CuI}$ under an $\mathrm{N}_{2}$ atmosphere in $\mathrm{EtOH}$ for the synthesis of polymer-supported CuI nanoparticles. This method was developed for the effective synthesis of copper nanoparticles incorporated heterogeneously as catalyst in the some organic reactions. ${ }^{32}$ Scanning electron microscopy (SEM), X-ray diffraction (XRD) analysis, atomic absorption and IR experimental techniques were used to characterize the catalyst. At first, for the optimization of the reaction conditions, the condensation of benzaldehyde, ethyl acetoacetate and urea was investigated under solvent-free conditions. The best result was achieved by carrying out the reaction of benzaldehyde, ethyl acetoacetate and urea (with 1: $1: 1: \mathrm{mol}$ ratio) in the presence of $0.1 \mathrm{~g}$ of $\mathrm{P}_{4} \mathrm{VPy}-\mathrm{CuI}$ at $80^{\circ} \mathrm{C}$ for $12 \mathrm{~min}$ under solventfree conditions (Table 1, entry 1). Using these optimized conditions, the reaction of various aromatic aldehydes was explored (Table 1). Aromatic aldehydes containing both electron-donating and electron-withdrawing groups were also reacted under the same reaction conditions to produce the corresponding DHPMs in good to high yields. Methyl acetoacetate and thiourea were also used with similar success to provide the corresponding products. Aliphatic aldehydes remain intact under the same reaction conditions (Table 1 entries 19, 20). Therefore, the method can be useful for the chemoselective Biginelli condensation of aromatic aldehydes in the presence of aliphatic ones (Table 1, entry 21). The experimental procedure with this catalyst is very simple and the catalyst can be removed easily by filtration. The solid products were easily recrystallized from hot ethanol and were obtained in good to high yields during short reaction times. Very low amount of the catalyst is needed. Moreover, our procedure is environmentally friendly as it does not use any toxic auxiliary or solvent. A distinct characterization of the present method, illustrated in this work is the formation of corresponding products without by-product. It is also noteworthy that catalyst do not suffer from extensive mechanical degradation after running. For a true heterogeneous catalyst, supported catalyst shouldn't leach to the reaction mixture. Moreover the recyclability of the supported catalyst is also important and shouldn't suffer from mechanical degradation. To investigate these properties, the reaction of benzaldehyde, ethyl acetoacetate and urea was selected again as the model (Table 2). After comple- 
Table 2. Recyclability of $\mathrm{P}_{4} \mathrm{VPy}-\mathrm{CuI}$

\begin{tabular}{lcccccccccc}
\hline Run & 1 & 2 & 3 & 4 & 5 & 6 & 7 & 8 & 9 & 10 \\
\hline Time(min) & 10 & 10 & 10 & 12 & 12 & 15 & 15 & 18 & 20 & 22 \\
Yield (\%) $^{a}$ & 92 & 92 & 91 & 90 & 90 & 89 & 89 & 89 & 89 & 88 \\
\hline
\end{tabular}

${ }^{a}$ Isolated yield.

tion of the reaction, the recovered catalyst was washed with acetone and after dryness was reused in the next similar run. This procedure was repeated for 10 consecutive runs and the the desired product was obtained in high yields after 1-10 runs, respectively (Tables 2 ). Next we checked the leaching of $\mathrm{CuI}$ into the reaction mixture from the poly(4-vinyl pyridine)-support using ICP-AES. The difference between the copper content of the fresh catalyst and the used catalyst (10th run) is only $3 \%$ which indicates the low leaching amount of copper iodide catalyst into the reaction mixture.

Finally, in order to evaluate the efficiency and superiority of our introduced catalyst, we began to run the reaction between benzaldehyde, ethyl acetoacetate and urea in the presence of pure $\mathrm{CuI}$ at the same conditions. The obtained results showed that pure $\mathrm{CuI}$ could not be reused, need much more reaction time and gave the product in the low yield. In conclusion, we have described a simple and green procedure for the synthesis of DHPMs catalyzed by $\mathrm{P}_{4} \mathrm{VPy}-\mathrm{CuI}$ under solvent-free conditions. The introduced catalyst can promote the yields and reaction times over 10 runs without appreciable loss in its activity and efficiency. Moreover, high yields of products, short reaction times, ease of work-up and clean procedure, will make this procedure a useful addition to the available methods.

Acknowledgments. We are thankful to to research council of Behbahan Khatam Alannbia University of Technology, for the partial support of this work. And the publication cost of this paper was supported by the Korean Chemical Society.

\section{REFERENCES}

1. Atwal, K. S.; Swanson, B. N.; Unger, S. E.; Floyd, D. M.; Moreland, S.; Hedberg, A.; O'Reilly, B. C. J. Med. Chem. 1991, 34, 806.

2. Biginelli, P. Gazz. Chim. Ital. 1893, 23, 360.

3. Paraskar, A. S.; Dewker, G. K.; Sudalai, A. Tetrahedron Lett. 2003, 44, 3305.

4. Kamal, A.; Krishnaji, T.; Azhar, M. A. Catal. Commun. 2007, 8, 1929.

5. Aridoss, G.; Jeong, Y. T. Bull. Korean. Chem. Soc. 2010, $31,863$.

6. Hekmatshoar, R.; Heidari, M.; Heravi, M. M.; Baghernezhad, B, J. Korean. Chem. Soc. 2009, 53, 90.
7. Hojati, S. F. Gholizadeh, M.; Haghdoust, M.; Shafiezadeh, F. Bull. Korean. Chem. Soc. 2010, 31, 1214.

8. Fang, Z.; Lam, Y. Tetrahedron Lett. 2011, 67, 1294.

9. Zeinali-Dastmalbaf, M.; Davoodnia, A.; Heravi, M. M.; Tavakoli-Hoseini, N.; Khojastehnezhad, A.; Zamani, H. A. Bull. Korean. Chem. Soc. 2011, 32, 656.

10. Rosati, O.; Curini, M.; Montanari, F.; Nocchetti, M,; Genovese, S. Cattal. Lett. 2011, 141, 850.

11. Salim, S. D.; Akamanchi, K. G. Catal. Lett. 2011, 122, 1153.

12. Heravi, M. M.; Bakhtiari, K.; Bamoharram, F. Catal. Commun. 2006, 7, 373.

13. Asgari, S.; Tajbakhsh, M.; Jafarzadeh Kenari, B.; Khaksar, S. Chin. Chem. Lett. 2011, 22, 127.

14. Pasunooti, K. K.; Chai, H.; Chantel Nixon, J.; Bala Kishan, G.; Siming, Wang.; Xue-Wei, L. Tetrahedron Lett. 2011, $52,80$.

15. Bigdeli, M. A.; Golami, G.; Sheikhhosseini, E. Chin. Chem. Lett. 2011, 22, 903.

16. Dharma Rao, G. B.; Acharya, B. N.; Verma, S. K.; Kaushik, M. P. Tetrahedron Lett. 2011, 52, 809.

17. Niknam, K.; Hassaninejad, A.; Arman, M. Chin. Chem. Lett. 2010, 21, 399.

18. Kalita, H. R. Phkan, P. Catal. Commun. 2007, 8, 179.

19. Gerard, B.; Ryan, J.; Beeler, A. B.; Porco, J. A. Tetrahedron. 2006, 62, 6405.

20. Marra, A.; Vecchi, A.; Chiappe, C.; Melai, B.; Dondoni, A. J. Org. Chem. 2008, 73, 2458.

21. Broggi, J.; Díez-González, S.; Petersen, J. L.; BerteinaRaboin, S.; Nolan, S. P.; Agrofoglio, L. A. Synthesis 2008, 141.

22. Lipshutz, B.; Taft, B. R. Angew. Chem. 2006, 118, 8415.

23. Girard, C.; Onen, E.; Aufort, M.; Beauvire, S.; Samson, E.; Erscovici, J. Org. Lett. 2006, 8, 1689.

24. Chassing, S.; Kumarraja, M.; Sido, A. S. S. S.; Pale, P.; Sommer, J. Org. Lett. 2007, 9, 883.

25. Miao, T.; Wang, L. Synthesis 2008, 363.

26. Park, I. S.; Kwon, M. S.; Kim, Y.; Lee, J. S.; Park, J. Org. Lett. 2008, 10, 497.

27. Tamami, B.; Parvanak Borujeni, K. Iran. Polymer. J. 2009, 18, 191.

28. Astruc, D. Nanoparticles and Catalysis; Wiley-VCH: Weinheim, 2008.

29. Albadi, J.; Keshavarz, M.; Abedini, M.; Vafaie-nezhad, M. Chin. Chem. Lett. 2012, 23, 797.

30. Albadi, J.; Keshavarz, M.; Shirini, F.; Vafaie-nezhad, M. Catal. Commun. 2012, 27, 17.

31. Shirini, F.; Zolfigol, M. A.; Albadi, J. Chin. Chem. Lett. 2011, 22, 318.

32. Sharghi, H.; Khalifeh, R.; Doroodmand, M. M. $A d v$. Synth. Catal. 2009, 351, 207. 